\title{
Computed tomography to estimate cardiac preload and extravascular lung water. A retrospective analysis in critically ill patients
}

Bernd Saugel ${ }^{1 *}$, Konstantin Holzapfel ${ }^{2}$, Jens Stollfuss ${ }^{3}$, Tibor Schuster ${ }^{4}$, Veit Phillip ${ }^{1}$, Caroline Schultheiss ${ }^{1}$, Roland M Schmid ${ }^{1}$ and Wolfgang Huber ${ }^{1}$

\begin{abstract}
Background: In critically ill patients intravascular volume status and pulmonary edema need to be quantified as soon as possible. Many critically ill patients undergo a computed tomography (CT)-scan of the thorax after admission to the intensive care unit (ICU). This study investigates whether CT-based estimation of cardiac preload and pulmonary hydration can accurately assess volume status and can contribute to an early estimation of hemodynamics.

Methods: Thirty medical ICU patients. Global end-diastolic volume index (GEDVI) and extravascular lung water index (EVLWI) were assessed using transpulmonary thermodilution (TPTD) serving as reference method (with established GEDVI/EVLWI normal values). Central venous pressure (CVP) was determined. CT-based estimation of GEDVI/EVLWI/CVP by two different radiologists (R1, R2) without analyzing software. Primary endpoint: predictive capabilities of CT-based estimation of GEDVI/EVLWI/CVP compared to TPTD and measured CVP. Secondary endpoint: interobserver correlation and agreement between R1 and R2.

Results: Accuracy of CT-estimation of GEDVI $\left(<680,680-800,>800 \mathrm{~mL} / \mathrm{m}^{2}\right)$ was $33 \%(\mathrm{R} 1) / 27 \%(\mathrm{R} 2)$. For R1 and R2 sensitivity for diagnosis of low GEDVI $\left(<680 \mathrm{~mL} / \mathrm{m}^{2}\right)$ was $0 \%$ (specificity $\left.100 \%\right)$. Sensitivity for prediction of elevated GEDVI (> $800 \mathrm{~mL} / \mathrm{m}^{2}$ ) was $86 \%(\mathrm{R} 1) / 57 \%(\mathrm{R} 2)$ with a specificity of $57 \%(\mathrm{R} 1) / 39 \%(\mathrm{R} 2)$ (positive predictive value $38 \%$ (R1)/22\%(R2); negative predictive value 93\%(R1)/75\%(R2)). Estimated CT-GEDVI and TPTD-GEDVI were significantly different showing an overestimation of GEDVI by the radiologists (R1: mean difference \pm standard error (SE): $191 \pm$ $30 \mathrm{~mL} / \mathrm{m}^{2}, \mathrm{p}<0.001$; R2: mean difference \pm SE: $\left.215 \pm 37 \mathrm{~mL} / \mathrm{m}^{2}, \mathrm{p}<0.001\right)$. CT GEDVI and TPTD-GEDVI showed a very low Lin-concordance correlation coefficient (ccc) (R1: $c c c=+0.20,95 \% \mathrm{Cl}:+0.00$ to +0.38 , bias-correction factor $(\mathrm{BCF})=0.52$; R2: $\mathrm{CcC}=-0.03,95 \% \mathrm{Cl}:-0.19$ to +0.12 , BCF $=0.42$ ). Accuracy of $\mathrm{CT}$ estimation in prediction of $\operatorname{EVLWI}(<7,7-10,>10 \mathrm{~mL} / \mathrm{kg})$ was $30 \%$ for R1 and 40\% for R2. CT-EVLWI and TPTD-EVLWI were significantly different (R1: mean difference \pm SE: $3.3 \pm 1.2 \mathrm{~mL} / \mathrm{kg}, \mathrm{p}=0.013$; R2: mean difference $\pm \mathrm{SE}: 2.8 \pm 1.1 \mathrm{~mL} / \mathrm{kg}, \mathrm{p}=$ 0.021). Again ccc was low with $-0.02(R 1 ; 95 \% \mathrm{Cl}:-0.20$ to +0.13 , $B C F=0.44)$ and +0.14 ( $R 2 ; 95 \% \mathrm{Cl}:-0.05$ to +0.32 , $\mathrm{BCF}=0.53)$. GEDVI, EVLWI and CVP estimations of R1 and R2 showed a poor interobserver correlation (low ccc) and poor interobserver agreement (low kappa-values).
\end{abstract}

Conclusions: CT-based estimation of GEDVI/EVLWI is not accurate for predicting cardiac preload and extravascular lung water in critically ill patients when compared to invasive TPTD-assessment of these variables.

\footnotetext{
* Correspondence: bcs.muc@gmx.de

'Il. Medizinische Klinik und Poliklinik, Klinikum rechts der Isar der Technischen Universität München, Ismaninger Strasse 22, D-81675 München, Germany

Full list of author information is available at the end of the article
}

\section{() Biomed Central}

(C) 2011 Saugel et al; licensee BioMed Central Ltd. This is an Open Access article distributed under the terms of the Creative Commons Attribution License (http://creativecommons.org/licenses/by/2.0), which permits unrestricted use, distribution, and reproduction in any medium, provided the original work is properly cited. 


\section{Background}

In order to guide volume resuscitation adequately, early assessment of intravascular and pulmonary fluid status is a crucial goal in the management of critically ill patients in the emergency department or the intensive care unit (ICU).

However, assessment of the volume status using physical examination procedures is difficult and often inaccurate in these patients [1-5].

Portable chest radiography can be used for a rough estimation of intravascular volume status as well as lung water and pulmonary edema [6-8]. However, for monitoring small changes in lung water or for quantification of pulmonary edema chest roentgenograms are not accurate $[7,8]$.

In ICU patients, invasive hemodynamic monitoring techniques are used for the assessment of hemodynamic variables. Transpulmonary thermodilution (TPTD) allows the measurement of cardiac preload (global enddiastolic volume index; GEDVI) and pulmonary fluid status (extravascular lung water index; EVLWI) [9-14].

In numerous studies the volumetric variable GEDVI has been shown to be accurate in the assessment of cardiac preload and volume responsiveness $[9,15,16]$. TPTD-based measurement of EVLWI has also been demonstrated to be accurate in animal studies compared to gravimetric measurements of extravascular lung water (EVLW) and in an autopsy study in humans compared to post-mortem lung weight $[11,12,14]$. In addition, there are data showing that EVLWI reflects severity of pulmonary disease and can predict outcome in patients with acute lung injury (ALI) or acute respiratory distress syndrome (ARDS) $[17,18]$.

Nevertheless, determination of GEDVI and EVLWI using TPTD requires an arterial access, resulting in risks for complications and restricting these methods to the ICU [19].

In contrast, computed tomography $(\mathrm{CT})$ has become a wide-spread diagnostic tool that is available even for non-ICU patients in many emergency departments. CT scanning of the thorax is very often performed due to basic clinical questions in the setting of critically ill patients in the first hours, frequently before establishing hemodynamic monitoring or admission to the ICU.

It has been shown that lung CT can help to understand the pathophysiology of ARDS and that it can influence clinical treatment decisions in ARDS patients [20-22]. One previous trial demonstrated that scoring systems based on CT lung morphology might help to identify patients with most severe forms of ARDS under study conditions [23].

Therefore, estimation of hemodynamic preload parameters and EVLWI using CT scans could potentially contribute to an early assessment of volume status, particularly in patients not (yet) under advanced hemodynamic monitoring.

The aim of our study was to investigate whether radiographic estimation of GEDVI, EVLWI and central venous pressure (CVP) using CT scanning of the thorax was able to contribute to an early, non-invasive estimation of hemodynamics in the clinical setting of critically ill patients. Radiographic estimation of GEDVI, EVLWI and CVP was compared to invasive assessment of these hemodynamic parameters using TPTD.

\section{Methods \\ Patients}

This was a retrospective analysis of a prospectively maintained TPTD database. We studied 30 critically ill patients treated in the medical ICU of a university hospital (Klinikum rechts der Isar, Technical University of Munich, Germany) who were examined by CT scanning of the thorax for clinical reasons unrelated to the study and who were monitored with TPTD using the PiCCOSystem (Pulsion Medical Systems AG, Munich, Germany) at the same time. The study was approved by the local ethics committee.

\section{CT}

30 CT scans (Siemens Volume-Zoom, Siemens Sensation, Siemens AG, Erlangen, Germany) of the 30 patients were independently analyzed by two experienced radiologists (radiologist $1=\mathrm{R} 1$ and radiologist 2 $=\mathrm{R} 2$ ). R1 and R2 were blinded to clinical findings and parameters determined by TPTD.

EVLWI was qualitatively estimated as elevated when engorged pulmonary vessels in the lung periphery exceeding the diameter of adjacent bronchi were seen. Thickening of bronchial walls secondary to excess fluid in the walls of the small airways (peribronchial cuffing), thickening of inter- and intralobular septae and groundclass opacities (i.e. areas of increased attenuation in the lung with preservation of bronchial and vascular markings) as features of interstitial pulmonary edema were considered indicative of moderately elevated EVLWI values (about 7-10 mL/kg). If consolidation of lung parenchyma (i.e. areas of increased attenuation in the lung with masking of bronchial and vascular markings accompanied by positive aerobronchogram) consistent with alveolar pulmonary edema was seen, EVLWI was classified as strongly elevated ( $>10 \mathrm{~mL} / \mathrm{kg}$ ). In addition, for estimation of EVLWI density of lung parenchyma measured in the periphery of upper, lower and middle lobe was considered (radiographic attenuation values of normally aerated lung: -500 to -900 Hounsfield units (HU), poorly aerated lung: -100 to $-500 \mathrm{HU}$, non-aerated lung: -100 to $+100 \mathrm{HU})[24,25]$. If larger areas of poorly and non-aerated lung were present, EVLWI was 
classified as strongly elevated (>10 mL/kg). EVLWI was estimated according to the criteria mentioned above. Within the three categories (EVLWI $<7,7-10,>10$ $\mathrm{mL} / \mathrm{kg}$ ) readers were asked to document a concrete value for EVLWI within the ranges mentioned based on subjective appreciation.

GEDVI was estimated by measuring the maximum short-axis diameter of right and left ventricle on axial images with diameters $>55 \mathrm{~mm}$ (left ventricle) and $>35$ $\mathrm{mm}$ (right ventricle) indicating elevated preload. If the maximum of the short-axis diameter of the left ventricle was $55-60 \mathrm{~mm}$ and/or the maximum diameter of the right ventricle was $35-45 \mathrm{~mm}$, GEDVI was classified as elevated (approximately $>800 \mathrm{~mL} / \mathrm{m}^{2}$ ). When diameters of left and right ventricle exceeded $60 \mathrm{~mm}$ and $45 \mathrm{~mm}$, respectively, GEDVI was classified as strongly elevated (approximately $>1000 \mathrm{~mL} / \mathrm{m}^{2}$ ). In addition, the configuration of the inferior vena cava on the level of the hepatic veins was considered for the radiographic estimation of GEDVI with a biconvex configuration of the inferior vena cava indicative of elevated GEDVI [26]. The radiologists were asked to document a concrete value for GEDVI within three categories (GEDVI < 680, 680 - 800, $>800 \mathrm{~mL} / \mathrm{m}^{2}$ ) based on subjective appreciation.

CVP values were quantitatively estimated by the radiologists based on subjective appreciation after evaluation of the filling of the inferior vena cava on the level of the hepatic veins [26].

In the clinical setting used in this trial, the average time for a radiologist to estimate EVLWI, GEDVI and CVP was about 5 minutes.

Twenty-eight of the 30 patients enrolled in this analysis received contrast medium $(70-90 \mathrm{~mL})$ for $\mathrm{CT}$ of the thorax.

\section{TPTD}

GEDVI and EVLWI were measured in triplicate based on TPTD using a 5-French thermistor-tipped arterial line (Pulsiocath, Pulsion Medical Systems AG) inserted in the femoral artery and a commercially available hemodynamic monitor (PiCCO-Plus; PiCCO-2, Pulsion Medical Systems AG) as described before [5,27]. Global end-diastolic volume (GEDV) was indexed to the body surface area and EVLW was indexed to the predicted body weight. In the patients included in the retrospective analysis, TPTD had been performed within a mean of 2.25 hours before or after the CT scan.

\section{Endpoints}

The primary endpoints were the diagnostic accuracy, sensitivity, specificity, positive predictive value (PPV) and negative predictive value (NPV) of radiologically estimated GEDVI and EVLWI regarding elevated and decreased values compared to TPTD-derived GEDVI and EVLWI.

The secondary endpoints were the interobserver correlation and agreement between the two radiologists and the analysis of radiologically estimated CVP compared to measured CVP and comparison of these parameters to GEDVI and EVLWI.

\section{Statistical analysis}

Diagnostic accuracy, sensitivity, specificity, PPV and NPV were calculated with corresponding $95 \%$ confidence intervals (95\% CI). The Spearman correlation coefficient (rho) was used to investigate bivariate correlations of quantitative measurements. Paired t-test was used to assess systematic differences in competitive measurements. To illustrate agreement of interesting measurements Bland-Altman figures and scatter plots with optimal reference line (45 degree) are provided [28]. The concordance correlation coefficient proposed by Lin (ccc) was used to evaluate agreement of quantitative measurements in consideration of accuracy and precision [29]. In this term the bias correction factor (BCF) was reported which measures how far the best-fit line deviates from the optimal line at 45 degrees (perfect agreement). No deviation from the 45 degree line occurs when $\mathrm{BCF}=1$ (possible range of values $>0$ to 1 ). Per definition Lin's ccc is determined by the product of Pearson correlation coefficient $(r)$ and the BCF $\left(\operatorname{ccc}=r^{*} B C F\right)$, thus both - information of systematical deviation and correlation of two measurements - is combined in one index, which takes values from -1 to 1 . Statistical analysis was performed using PASW Statistics (version 17; SPSS inc., Chicago, Illinois, USA) and the statistical software package $\mathrm{R}$ version 2.7.1 (R Foundation for Statistical Computing, Vienna, Austria). All tests were conducted two-sided and statistical significance was considered at $\mathrm{p}<0.05$.

\section{Results}

\section{Patients and patients' characteristics}

Thirty critically ill ICU patients were enrolled in this study. The patients' basic demographic data and clinical characteristics including reason for ICU admission, ICU treatment, laboratory tests, and ICU outcome are presented in Table 1.

\section{TPTD results}

At the time of enrollment, mean TPTD-derived GEDVI was $685 \pm 154 \mathrm{~mL} / \mathrm{m}^{2}$ (range: 412 to $1044 \mathrm{~mL} / \mathrm{m}^{2}$ ), mean TPTD-derived EVLWI was $11.6 \pm 6.4 \mathrm{~mL} / \mathrm{kg}$ (range: 4 to $38 \mathrm{~mL} / \mathrm{kg}$ ), and mean measured CVP was $15.9 \pm 6.3 \mathrm{mmHg}$ (range: 4 to $32 \mathrm{mmHg}$ ). The distribution of GEDVI, EVLWI, and CVP values categorized according to the used thresholds is presented in Table 2. 
Table 1 Patients' demographic data, patients' clinical characteristics, and reason for intensive care unit admission

\begin{tabular}{|c|c|}
\hline \multicolumn{2}{|l|}{ Basic demographic data } \\
\hline Sex (female/male) & $14 / 16$ \\
\hline Age, years & $66(27-83)$ \\
\hline Height, cm & $170(150-180)$ \\
\hline Weight, kg & $68(44-112)$ \\
\hline \multicolumn{2}{|c|}{ Patients' clinical characteristics on the day of enrollment in the study } \\
\hline Simplified Acute Physiology Score (SAPS-II) & $50(22-63)$ \\
\hline Therapeutic Intervention Scoring System (TISS-score) & $22(10-35)$ \\
\hline Serum creatinine, mg/dL & $1.8(0.5-4.6)$ \\
\hline Blood urea nitrogen, $\mathrm{mg} / \mathrm{dL}$ & $52(8-106)$ \\
\hline Serum bilirubin, mg/dL & $2.7(0.3-23.2)$ \\
\hline Aspartate aminotransferase, U/L & $122(11-4977)$ \\
\hline Leukocyte count, G/L & $16.2(0.1-50.0)$ \\
\hline C-reactive proteine, $\mathrm{mg} / \mathrm{dL}$ & $7.9(0.1-45.7)$ \\
\hline Hematocrit level, \% & $29(23-47)$ \\
\hline Hemoglobin, g/dL & $9.9(7.3-16.0)$ \\
\hline Heart rate, beats per minute & $94(57-144)$ \\
\hline Need for catecholamine therapy, $\mathrm{n}(\%)$ & $23(77 \%)$ \\
\hline Norepinephrine dose, $\mu \mathrm{g} / \mathrm{kg} / \mathrm{min}$ & $0.16(0-1.89)$ \\
\hline Need for mechanical ventilation, $\mathrm{n}(\%)$ & $25(83 \%)$ \\
\hline Positive end-expiratory pressure, $\mathrm{CmH}_{2} \mathrm{O}$ & $8(4-16)$ \\
\hline Peak pressure, $\mathrm{CmH}_{2} \mathrm{O}$ & $24(13-31)$ \\
\hline Mean airway pressure, $\mathrm{cmH}_{2} \mathrm{O}$ & $14(7-21)$ \\
\hline Fraction of inspired oxygen & $0.5(0.3-1.0)$ \\
\hline Tidal volume, $\mathrm{mL}$ & $500(300-842)$ \\
\hline $\mathrm{pH}$ & $7.33(7.18-7.60)$ \\
\hline Arterial partial pressure of carbon dioxide, $\mathrm{mmHg}$ & $37.0(21.0-64.5)$ \\
\hline Arterial partial pressure of oxygen, $\mathrm{mmHg}$ & $89.1(58.0-160.0)$ \\
\hline Bicarbonate, mEq/L & $20.9(11.4-36.4)$ \\
\hline Base excess, mEq/L & $-3.9(-14.1-11.7)$ \\
\hline \multicolumn{2}{|l|}{ Reason for ICU admission } \\
\hline Sepsis with multiple organ dysfunction syndrome, n (\%) & $9(30 \%)$ \\
\hline Pneumonia and acute respiratory insufficiency, n (\%) & $8(27 \%)$ \\
\hline Cirrhosis of the liver, n (\%) & $4(13 \%)$ \\
\hline Pancreatitis, n (\%) & $3(10 \%)$ \\
\hline Cardiac arrest with need for cardiopulmonary resuscitation, n (\%) & $2(7 \%)$ \\
\hline Gastrointestinal bleeding, n (\%) & $2(7 \%)$ \\
\hline Renal failure, n (\%) & $1(3 \%)$ \\
\hline Pulmonary embolism, n (\%) & $1(3 \%)$ \\
\hline \multicolumn{2}{|l|}{ Outcome } \\
\hline Intensive care unit mortality, n (\%) & $17(57 \%)$ \\
\hline
\end{tabular}

Data are presented as median (range) where applicable. ICU, intensive care unit.

\section{CT-scan results}

Estimation of GEDVI based on $\mathrm{CT}$ resulted in a mean estimated GEDVI of $877 \pm 137 \mathrm{~mL} / \mathrm{m}^{2}$ (range: 700 to $1100 \mathrm{~mL} / \mathrm{m}^{2}$ ) for $\mathrm{R} 1$ and $900 \pm 117 \mathrm{~mL} / \mathrm{m}^{2}$ (range: 750 to $1100 \mathrm{~mL} / \mathrm{m}^{2}$ ) for $\mathrm{R} 2$. Mean radiologically estimated
EVLWI was $8.3 \pm 1.9 \mathrm{~mL} / \mathrm{kg}$ (range: 5 to $12 \mathrm{~mL} / \mathrm{kg}$ ) (R1) and $8.9 \pm 2.2 \mathrm{~mL} / \mathrm{kg}$ (range: 5 to $14 \mathrm{~mL} / \mathrm{kg}$ ) (R2). Mean CVP estimated by R1 and R2 was $8.6 \pm 2.3 \mathrm{mmHg}$ (range: 5 to $12 \mathrm{mmHg}$ ) and $8.2 \pm 2.2 \mathrm{mmHg}$ (range: 5 to 14 $\mathrm{mmHg}$ ), respectively. In Table 3 the distribution of 
Table 2 Transpulmonary thermodilution-derived hemodynamic variables and measured central venous pressure

\begin{tabular}{|c|c|c|}
\hline \multicolumn{3}{|l|}{ TPTD-derived GEDVI } \\
\hline $\begin{array}{l}\text { GEDVI }<680 \mathrm{~mL} / \mathrm{m}^{2}, \\
\mathrm{n}(\%)\end{array}$ & $\begin{array}{l}\text { GEDVI } 680-800 \mathrm{~mL} / \mathrm{m}^{2} \text {, } \\
\mathrm{n}(\%)\end{array}$ & $\begin{array}{l}\text { GEDVI }>800 \mathrm{~mL} / \mathrm{m}^{2}, \\
\mathrm{n}(\%)\end{array}$ \\
\hline $14(47 \%)$ & $9(30 \%)$ & $7(23 \%)$ \\
\hline \multicolumn{3}{|l|}{ TPTD-derived EVLWI } \\
\hline $\begin{array}{l}\mathrm{EVLWI}<7 \mathrm{~mL} / \mathrm{kg} \\
\mathrm{n}(\%)\end{array}$ & $\begin{array}{l}\mathrm{EVLWI}=7-10 \mathrm{~mL} / \mathrm{kg} \\
\mathrm{n}(\%)\end{array}$ & $\begin{array}{l}\mathrm{EVLWI}>10 \mathrm{~mL} / \mathrm{kg} \\
\mathrm{n}(\%)\end{array}$ \\
\hline $5(17 \%)$ & $11(37 \%)$ & $14(47 \%)$ \\
\hline \multicolumn{3}{|l|}{ CVP (measured) } \\
\hline CVP $<$ or $=9 \mathrm{mmHg}$ & $\mathrm{CVP}>9 \mathrm{mmHg}$ & \\
\hline $5(17 \%)$ & $25(83 \%)$ & \\
\hline
\end{tabular}

Distribution of transpulmonary thermodilution (TPTD)-derived values of global end-diastolic volume index (GEDVI) and extravascular lung water index (EVLWI) as well as values of measured central venous pressure (CVP) according to the used thresholds. Data are presented as absolute numbers ( $n$ ) with percentages in parentheses.

estimated GEDVI, EVLWI, and CVP values categorized according to the used thresholds is shown.

\section{Comparison of CT-based estimations of the two radiologists ( $\mathrm{R} 1$ and $\mathrm{R} 2$ )}

Comparison of the two radiologists' estimations of GEDVI, EVLWI and CVP without any categorization and determination of the interobserver correlation showed a low ccc for all three variables (GEDVI: ccc $=$ $+0.64,95 \%$ CI: +0.38 to +0.81 , BCF of 0.97; EVLWI: ccc $=+0.63,95 \% \mathrm{CI}:+0.37$ to +0.80 , BCF of 0.96; CVP: $\mathrm{ccc}$ $=+0.63,95 \% \mathrm{CI}:+0.36$ to +0.80 , BCF of 0.99$)$. After categorization of the radiologists' estimations of GEDVI, EVLWI and CVP (GEDVI < 680, $680-800,>800 \mathrm{~mL} /$ $\mathrm{m}^{2} ; \mathrm{EVLWI}<7$ or $>/=7 \mathrm{~mL} / \mathrm{kg} ; \mathrm{CVP} 1-9$ or $>9$ $\mathrm{mmHg}$ ) the interobserver agreement showed poor kappa-values (GEDVI: kappa $=0.46$; EVLWI: kappa $=$ 0.71; CVP: kappa $=0.53$ ).

\section{Comparison of TPTD-GEDVI vs. GEDVI estimated using CT scan}

GEDVI values estimated by the radiologists and TPTDderived GEDVI values were significantly different (R1: mean difference \pm standard error (SE): $191 \pm 30 \mathrm{~mL} / \mathrm{m}^{2}, \mathrm{p}$ $<0.001$; R2: mean difference \pm SE: $215 \pm 37 \mathrm{~mL} / \mathrm{m}^{2}, \mathrm{p}<$ 0.001 ) with an overestimation of radiographic estimated GEDVI values in $90 \%$ of false estimations (Figure 1). Comparison of GEDVI values estimated using CT and TPTDderived GEDVI values showed a very low ccc (R1: ccc = $+0.20,95 \% \mathrm{CI}:+0.00$ to +0.38 ; R2: $\mathrm{ccc}=-0.03,95 \% \mathrm{CI}$ : -0.19 to +0.12 ) with a BCF of 0.52 (R1) and 0.42 (R2). To evaluate the individual agreement between radiographic estimations of GEDVI and TPTD assessment of GEDVI, a Bland-Altman figure is presented in Figure 2. Diagnostic accuracy of radiographic estimation of GEDVI (after categorization of GEDVI in 3 categories: GEDVI < 680, 680 $800,>800 \mathrm{~mL} / \mathrm{m}^{2}$ ) using CT of the thorax was $33 \%$ (R1; 95\% CI: $17 \%$ to $53 \%$ ) and $27 \%$ (R2; $95 \%$ CI: $12 \%$ to $46 \%)$. Despite a number of markedly decreased TPTD-GEDVI measurements, none of the radiologists classified any GEDVI value as decreased. Table 4 shows predictive capabilities of CT-based GEDVI estimation with regard to GEDVI derived from TPTD.

\section{Comparison of TPTD-EVLWI vs. EVLWI estimation based on CT scan}

Radiographic estimation of EVLWI according to the used thresholds (EVLWI $<7,7-10,>10 \mathrm{~mL} / \mathrm{kg}$ )

Table 3 Computed tomography-based estimation of hemodynamic parameters

\begin{tabular}{|c|c|c|c|}
\hline \multicolumn{4}{|c|}{ CT-based estimation of hemodynamic variables } \\
\hline & \multicolumn{3}{|l|}{ GEDVI (estimated) } \\
\hline & $\begin{array}{l}\text { GEDVI }<680 \mathrm{~mL} / \mathrm{m}^{2}, \\
\mathrm{n}(\%)\end{array}$ & $\begin{array}{l}\text { GEDVI } 680-800 \mathrm{~mL} / \mathrm{m}^{2} \text {, } \\
\mathrm{n}(\%)\end{array}$ & $\begin{array}{l}\text { GEDVI > } 800 \mathrm{~mL} / \mathrm{m}^{2}, \\
\mathrm{n}(\%)\end{array}$ \\
\hline R1 & $0(0 \%)$ & $14(47 \%)$ & $16(53 \%)$ \\
\hline \multirow[t]{3}{*}{$\mathrm{R} 2$} & $0(0 \%)$ & $12(40 \%)$ & $18(60 \%)$ \\
\hline & \multicolumn{3}{|l|}{ EVLWI (estimated) } \\
\hline & $\begin{array}{l}\mathrm{EVLWl}<7 \mathrm{~mL} / \mathrm{kg} \\
\mathrm{n}(\%)\end{array}$ & $\begin{array}{l}\mathrm{EVLWI}=7-10 \mathrm{~mL} / \mathrm{kg}, \\
\mathrm{n}(\%)\end{array}$ & $\begin{array}{l}\text { EVLWI > } 10 \mathrm{~mL} / \mathrm{kg} \\
\mathrm{n}(\%)\end{array}$ \\
\hline R1 & $4(13 \%)$ & $21(70 \%)$ & $5(17 \%)$ \\
\hline \multirow[t]{3}{*}{ R2 } & $4(13 \%)$ & $19(63 \%)$ & $7(23 \%)$ \\
\hline & \multicolumn{3}{|l|}{ CVP (estimated) } \\
\hline & $\mathrm{CVP}<$ or $=9 \mathrm{mmHg}$ & \multicolumn{2}{|l|}{$\mathrm{CVP}>9 \mathrm{mmHg}$} \\
\hline R1 & $20(67 \%)$ & \multicolumn{2}{|l|}{$10(33 \%)$} \\
\hline R2 & $22(73 \%)$ & \multicolumn{2}{|l|}{$8(27 \%)$} \\
\hline
\end{tabular}

Distribution of radiographically estimated values of global end-diastolic volume index (GEDVI), extravascular lung water index (EVLWI), and central venous pressure (CVP) according to the used thresholds. Data are presented as absolute numbers (n) with percentages in parentheses. CT, computed tomography; R1, radiologist $1 ; R 2$, radiologist 2 . 


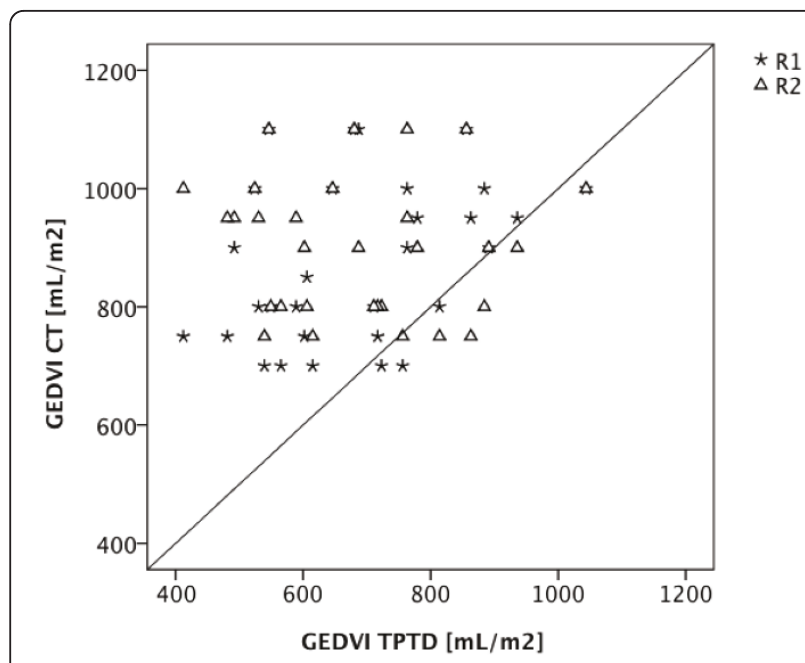

Figure 1 CT-based GEDVI estimation compared to TPTDderived GEDVI. Scatter plot showing GEDVI values derived from TPTD (GEDVI TPTD) compared to GEDVI estimations based on CT scans (GEDVI CT) by radiologist 1 (R1) and radiologist 2 (R2).

showed a diagnostic accuracy of 30\% (R1; 95\% CI: $14 \%$ to $46 \%$ ) and $40 \%$ (R2; $95 \%$ CI: $22 \%$ to $58 \%$ ), respectively. Sensitivity, specificity, PPV, and NPV for CT-based estimations of EVLWI for R1 and R2 are shown in Table 5. EVLWI estimated using CT and TPTD-derived EVLWI were significantly different (R1: mean difference \pm SE: $3.3 \pm 1.2 \mathrm{~mL} / \mathrm{kg}, \mathrm{p}=0.013 ; \mathrm{R} 2$ : mean difference $\pm \mathrm{SE}$ :

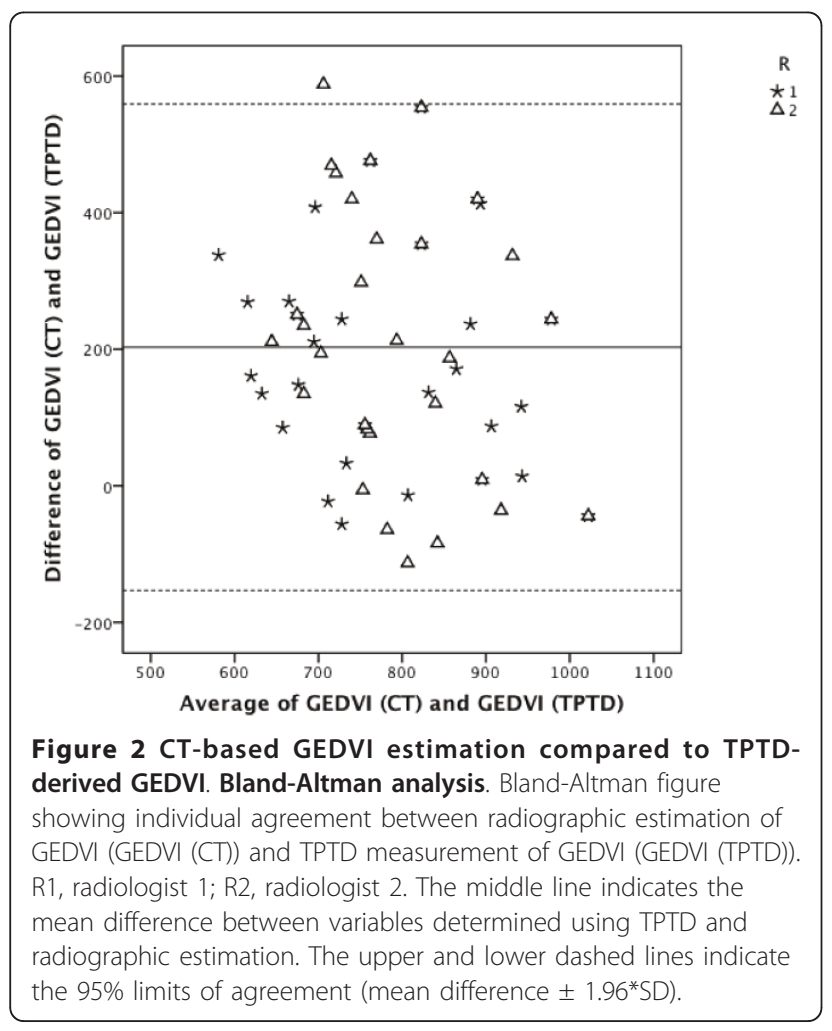

$2.8 \pm 1.1 \mathrm{~mL} / \mathrm{kg}, \mathrm{p}=0.021$ ) (Figure 3). ccc was low with -0.02 (R1; 95\% CI: -0.20 to +0.13 , BCF of 0.44 ) and +0.14 (R2; $95 \%$ CI: -0.05 to +0.32 , BCF of 0.53 ). The corresponding Bland-Altman figure is presented in Figure 4.

\section{Comparison of CVP vs. radiographic CVP estimation}

The prediction of CVP (CVP 1 - 9 or $>9 \mathrm{mmHg}$ ) estimated using CT showed a diagnostic accuracy of only $43 \%$ for both radiologists. Sensitivity for prediction of elevated CVP (CVP > $9 \mathrm{mmHg}$ ) was only $36 \%$ (R1) and $32 \%$ (R2) with a specificity of $80 \%$ (R1) and $100 \%$ (R2) (table 6). PPV for prediction of elevated CVP was $90 \%$ (R1) and 100\% (R2). NPV was 20\% (R1) and 23\% (R2). CVP estimated by the radiologist using CT and assessed CVP were significantly different (R1: mean difference \pm SE: $7.3 \pm 1.1 \mathrm{mmHg}, \mathrm{p}<0.001$; R2: mean difference \pm SE: $7.6 \pm 1.1 \mathrm{mmHg}, \mathrm{p}<0.001)$. ccc was again low with +0.08 (R1; $95 \%$ CI: -0.03 to +0.19 , BCF of 0.29 ) and +0.11 (R2; 95\% CI: -0.01 to +0.21 , BCF of 0.27 ).

\section{Comparison CVP vs. GEDVI in prediction of volume status} Measured CVP was analyzed with regard to measured GEDVI. For predicting TPTD-derived volume status (GEDVI $<680,680-800,>800 \mathrm{~mL} / \mathrm{m}^{2}$ ) the assessment of CVP $(\mathrm{CVP}<1,1-9$, $>9 \mathrm{mmHg})$ showed a diagnostic accuracy of $27 \%$ with a NPV for hypovolemic fluid status (GEDVI $<680 \mathrm{~mL} / \mathrm{m}^{2}$ ) of $53 \%$ (sensitivity $0 \%$, specificity $100 \%$, PPV 0\%). CVP values and GEDVI values did not significantly correlate (Spearman's correlation coefficient rho $=-0.143, \mathrm{p}=0.45$ ).

In addition CVP did not significantly correlate to EVLWI values assessed by TPTD (Spearman's correlation coefficient rho $=+0.222, \mathrm{p}=0.24)$. The CVP showed a diagnostic accuracy in estimation of EVLWI of $83 \%$. Sensitivity for prediction of pulmonary edema/ fluid overload (EVLWI $>/=7 \mathrm{ml} / \mathrm{kg} ; \mathrm{CVP}>9 \mathrm{mmHg}$ ) was $88 \%$ (specificity $40 \%$, PPV $88 \%$, NPV $40 \%$ ).

\section{Discussion}

CT scans of the thorax are frequently performed in critically ill patients during the first hours in the emergency department or after ICU admission even before hemodynamic monitoring can be established. Therefore, using routine CT scans, CT-based estimation of preload and pulmonary fluid status might have considerable impact on early volume resuscitation in critically ill patients.

This study investigated whether radiographic estimation (by two independent radiologists) of GEDVI, EVLWI and CVP using CT scans of the thorax is able to evaluate intravascular and pulmonary fluid status in critically ill patients. To obtain representative data in a clinical routine setting, we did not use analyzing 
Table 4 Predictive capabilities of computed tomography-based estimation of global end-diastolic volume index

\begin{tabular}{|c|c|c|c|c|}
\hline & & \multicolumn{3}{|c|}{ CT-based estimation of GEDVI vs. TPTD-derived GEDVI } \\
\hline & & GEDVI $<680 \mathrm{~mL} / \mathrm{m}^{2}$ & GEDVI $=680-800 \mathrm{~mL} / \mathrm{m}^{2}$ & GEDVI $>800 \mathrm{~mL} / \mathrm{m}^{2}$ \\
\hline \multirow[t]{4}{*}{ Radiologist 1} & Sensitivity & $\begin{array}{c}0 \\
\text { (0 to } 23)\end{array}$ & $\begin{array}{c}44 \\
(14 \text { to } 79)\end{array}$ & $\begin{array}{c}86 \\
\text { (42 to } 99)\end{array}$ \\
\hline & Specificity & $\begin{array}{c}100 \\
\text { (79 to } 100)\end{array}$ & $\begin{array}{c}52 \\
\text { (30 to } 74)\end{array}$ & $\begin{array}{c}57 \\
\text { (34 to } 77 \text { ) } \\
\end{array}$ \\
\hline & PPV & not estimable due to zero counts in numerator & $\begin{array}{c}29 \\
\text { (8 to } 58)\end{array}$ & $\begin{array}{c}38 \\
\text { (15 to } 65) \\
\end{array}$ \\
\hline & NPV & $\begin{array}{c}53 \\
\text { (34 to 72) } \\
\end{array}$ & $\begin{array}{c}69 \\
\text { (41 to } 89) \\
\end{array}$ & $\begin{array}{c}93 \\
\text { (66 to 99) } \\
\end{array}$ \\
\hline \multirow[t]{4}{*}{ Radiologist 2} & Sensitivity & $\begin{array}{c}0 \\
\text { (0 to 23) }\end{array}$ & $\begin{array}{c}44 \\
\text { (14 to } 79)\end{array}$ & $\begin{array}{c}57 \\
\text { (18 to 90) }\end{array}$ \\
\hline & Specificity & $\begin{array}{c}100 \\
\text { (79 to } 100)\end{array}$ & $\begin{array}{c}62 \\
\text { (38 to } 82 \text { ) }\end{array}$ & $\begin{array}{c}39 \\
(20 \text { to } 61)\end{array}$ \\
\hline & PPV & not estimable due to zero counts in numerator & $\begin{array}{c}33 \\
(10 \text { to } 65)\end{array}$ & $\begin{array}{c}22 \\
\text { (6 to } 48)\end{array}$ \\
\hline & NPV & $\begin{array}{c}53 \\
\text { (34 to } 72)\end{array}$ & $\begin{array}{c}72 \\
(47 \text { to } 90)\end{array}$ & $\begin{array}{c}75 \\
\text { (43 to 95) }\end{array}$ \\
\hline
\end{tabular}

Sensitivity, specificity, positive predictive value (PPV), negative predictive value (NPV) given as percentages with $95 \%$ confidence intervals (95\% Cl) in parentheses for computed tomography (CT)-based estimations of global end-diastolic volume index (GEDVI) with regard to GEDVI derived from transpulmonary thermodilution (TPTD) are shown separately for radiologist 1 and radiologist 2 .

software, and the radiologists were totally blinded to clinical, laboratory and TPTD-derived information. The main results of this study can be summarized as follows: In critically ill patients estimation of hemodynamic parameters (GEDVI, EVLWI) or CVP using CT is not accurate when compared to invasive assessment of these variables using TPTD or CVP measurement, respectively. TPTD-derived values for GEDVI and EVLWI were significantly different from GEDVI and EVLWI values estimated using CT. Estimation of GEDVI is not satisfactorily accurate, sensitive or specific for prediction of a hypovolemic volume status (defined by TPTD, GEDVI $<680 \mathrm{~mL} / \mathrm{m}^{2}$ ). Regarding prediction of hypervolemia (GEDVI $>800 \mathrm{~mL} / \mathrm{m}^{2}$ ) radiographic estimation showed slightly better predictive capabilities with low PPVs. For predicting EVLWI and CVP the radiographic estimation is not sufficiently accurate, sensitive or specific.

These results are partially in contrast to previous studies.

Table 5 Predictive capabilities of computed tomography-based estimation of extravascular lung water index

\begin{tabular}{|c|c|c|c|c|}
\hline & & \multicolumn{3}{|c|}{ CT-based estimation of EVLWI vs. TPTD-derived EVLWI } \\
\hline & & EVLWI $<7 \mathrm{~mL} / \mathrm{kg}$ & EVLWI $7-10 \mathrm{~mL} / \mathrm{kg}$ & EVLWI $>10 \mathrm{~mL} / \mathrm{kg}$ \\
\hline \multirow[t]{4}{*}{ Radiologist 1} & Sensitivity & $\begin{array}{c}20 \\
\text { (0.5 to } 72)\end{array}$ & $\begin{array}{c}64 \\
\text { (31 to } 89)\end{array}$ & $\begin{array}{c}7 \\
(0.1 \text { to } 34)\end{array}$ \\
\hline & Specificity & $\begin{array}{c}88 \\
\text { (69 to 97) }\end{array}$ & $\begin{array}{c}26 \\
\text { (9 to } 51)\end{array}$ & $\begin{array}{c}75 \\
\text { (48 to 93) }\end{array}$ \\
\hline & PPV & $\begin{array}{c}25 \\
(0.6 \text { to } 81) \\
\end{array}$ & $\begin{array}{c}33 \\
(15 \text { to } 57) \\
\end{array}$ & $\begin{array}{c}20 \\
(0.5 \text { to } 72) \\
\end{array}$ \\
\hline & NPV & $\begin{array}{c}85 \\
\text { (65 to } 96)\end{array}$ & $\begin{array}{c}56 \\
\text { (21 to } 86)\end{array}$ & $\begin{array}{c}48 \\
\text { (28 to 69) }\end{array}$ \\
\hline \multirow[t]{4}{*}{ Radiologist 2} & Sensitivity & $\begin{array}{c}20 \\
\text { (0.5 to } 72)\end{array}$ & $\begin{array}{c}64 \\
\text { (31 to } 89 \text { ) }\end{array}$ & $\begin{array}{c}29 \\
\text { (8 to } 58)\end{array}$ \\
\hline & Specificity & $\begin{array}{c}88 \\
\text { (69 to 97) }\end{array}$ & $\begin{array}{c}37 \\
(16 \text { to } 62)\end{array}$ & $\begin{array}{c}81 \\
\text { (54 to 96) }\end{array}$ \\
\hline & PPV & $\begin{array}{c}25 \\
\text { (0.6 to } 81)\end{array}$ & $\begin{array}{c}37 \\
\text { (16 to } 62) \\
\end{array}$ & $\begin{array}{c}57 \\
\text { (18 to 90) }\end{array}$ \\
\hline & NPV & $\begin{array}{c}85 \\
(65 \text { to } 96)\end{array}$ & $\begin{array}{c}64 \\
\text { (31 to } 89)\end{array}$ & $\begin{array}{c}57 \\
\text { (34 to 77) }\end{array}$ \\
\hline
\end{tabular}

Sensitivity, specificity, positive predictive value (PPV), negative predictive value (NPV) given as percentages with 95\% confidence intervals $(95 \% \mathrm{CI})$ in parentheses for computed tomography (CT)-based estimations of extravascular lung water index (EVLWI) with regard to EVLWI derived from transpulmonary thermodilution (TPTD) are shown separately for radiologist 1 and radiologist 2. 


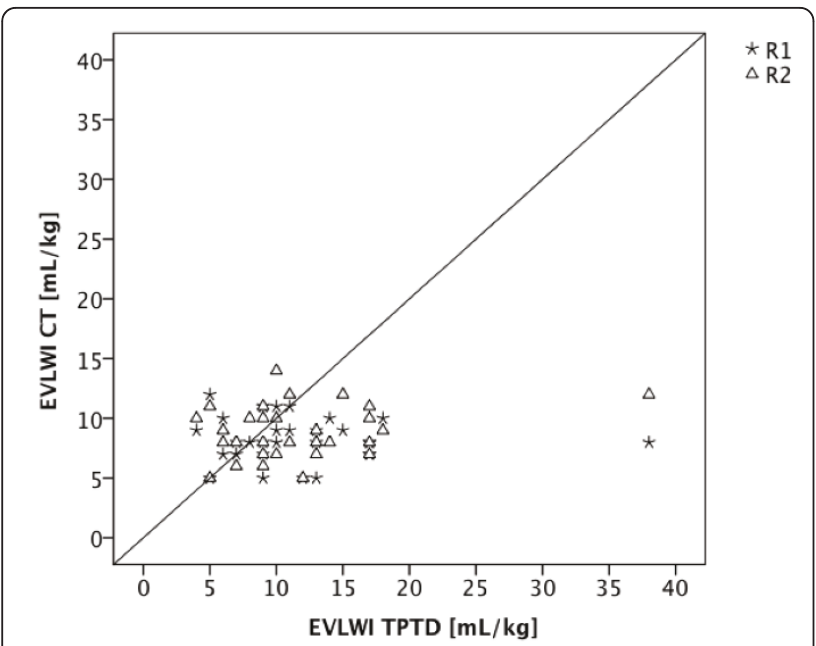

Figure 3 CT-based EVLWI estimation compared to TPTDderived EVLWI. Scatter plot showing EVLWI values determined by TPTD (EVLWI TPTD) compared to EVLWI estimation based on CT scans (EVLWI CT) by radiologist 1 (R1) and radiologist 2 (R2).

A recently published animal study by Kuzkov et al. found an association of lung tissue volume assessed by quantitative CT and EVLWI (determined by TPTD and postmortem gravimetry) in 7 sheep with ALI [30]. However, it has been demonstrated that EVLWI data obtained in animal models are not easily transferable to humans because a species-specific correction factor

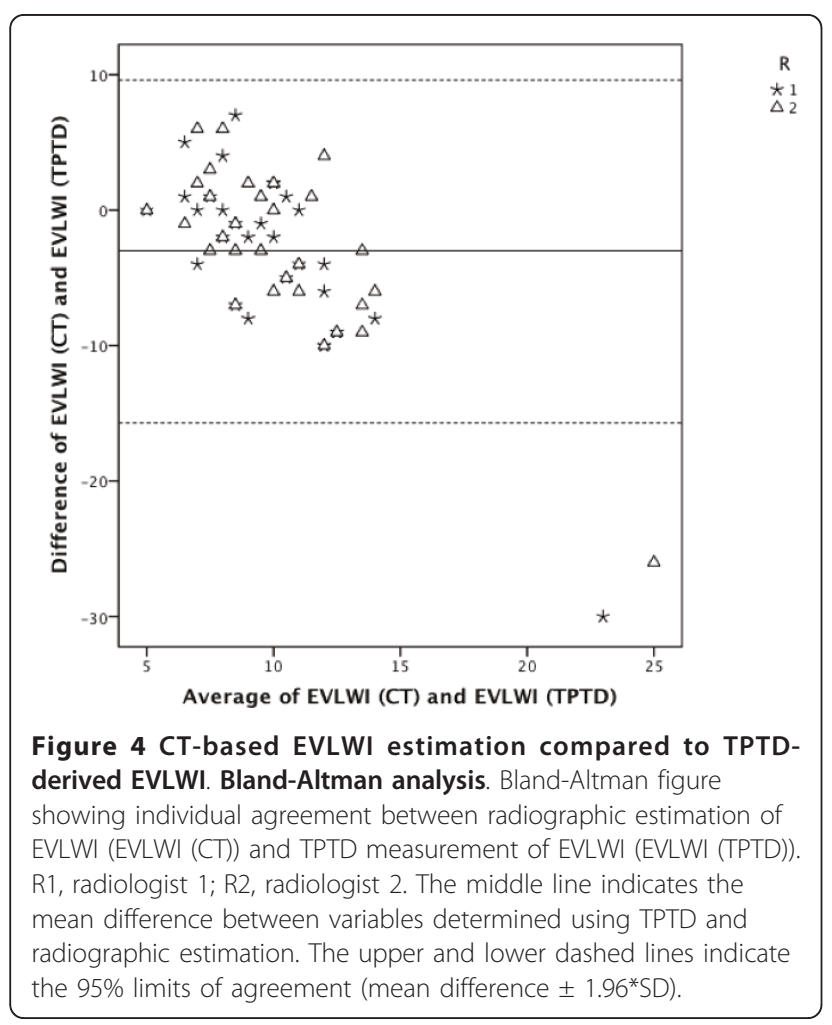

might be needed for the calculation of EVLWI [31,32]. Correspondingly, another animal study in dogs found that EVLWI values markedly increased when ALI was induced whereas lung tissue density assessed by CT did not alter [33].

In contrast to the results of our clinical study, there are data from an in-vitro study using a lung specimen suggesting that accurate assessment of lung water can be achieved by $\mathrm{CT}$ scanning using analyzing software under study conditions [34]. However, these results are hardly transferable to critically ill patients, because the study was conducted using special analyzing software and a lung model (air-dried, ex-sanguine human lung).

In a case-series of patients with ARDS quantification of lung edema by computed tomography using dedicated analyzing software showed a good correlation with measurements of lung edema using the thermal indocyanine green-dye double-dilution method [35]. However this study performed in an experimental setting was restricted to 14 patients and used experimental analyzing software for CT-based estimation of EVLW, which is not routinely available and therefore does not reflect standard clinical conditions. By contrast, our protocol was deliberately aimed at routine standard conditions and the radiologists read the CT scans in a clinical setting without the support of quantitative $\mathrm{CT}$ analyzing software. In contrast to previous studies, the predictive capabilities of radiographic estimation of hemodynamic parameters observed in the present study are therefore applicable to a realistic clinical routine setting.

In our study the investigating radiologists were completely blinded to the clinical and laboratory data of the patients in order to exclude suggestive data related to the pre-existing hemodynamic status. This might have impaired the radiological estimation when compared to clinical routine.

In the present trial CT-based estimation of CVP was not sufficiently accurate, sensitive or specific. However, regarding the use of CVP values for the assessment of cardiac preload there is increasing evidence that several factors can influence CVP determination in critically ill patients and that CVP is therefore not able to reflect cardiac preload and predict volume responsiveness $[9,36]$. For example, CVP can be overestimated in patients with increased intraabdominal pressure or mechanical ventilation with high positive end-expiratory pressure [37].

One might argue that cardiac volume and pulmonary vascular status might have been affected by the fast intravenous injection of about $70-90 \mathrm{~mL}$ of contrastmedium potentially resulting in an overestimation of cardio-pulmonary filling. However, 12 of the 30 TPTD measurements were performed before the application of contrast-medium, thus excluding a bias by contrast injection. 
Table 6 Predictive capabilities of computed tomography-based estimation of central venous pressure

\begin{tabular}{cccccccc}
\hline & CVP CT (R1) vs. CVP & $\mathbf{9 5 \%}$ Cl lower & $\mathbf{9 5 \%}$ Cl upper & & CVP CT (R2) vs. CVP & 95\% Cl lower & 95\% Cl upper \\
\hline Sensitivity & $36 \%$ & $17 \%$ & $55 \%$ & Sensitivity & $32 \%$ & $14 \%$ & $50 \%$ \\
\hline Specificity & $80 \%$ & $45 \%$ & $>99 \%$ & Specificity & $100 \%$ & $49 \%$ & $100 \%$ \\
\hline PPV & $90 \%$ & $71 \%$ & $>99 \%$ & PPV & $100 \%$ & $63 \%$ & $100 \%$ \\
\hline NPV & $20 \%$ & $3 \%$ & $38 \%$ & NPV & $23 \%$ & $5 \%$ & $40 \%$ \\
\hline
\end{tabular}

Sensitivity, specificity, positive predictive value (PPV), negative predictive value (NPV) and 95\% confidence intervals (95\% CI) for computed tomography (CT)based estimations of central venous pressure (CVP CT) with regard to measured elevation of central venous pressure (CVP; CVP > 9 mmHg) are shown. CVP CT is separately shown for radiologist 1 (R1) and radiologist 2 (R2).

Finally, failure of CT-based estimation to exactly predict hemodynamic parameters does not necessarily mean that CT can not provide important data improving the interpretation of hemodynamic measurements. For example, CT might be useful in the interpretation of elevated EVLWI resulting from inflammation or cardiac congestion. Furthermore, interdisciplinary training of the radiologists and further development of diagnostic algorithms might improve radiological assessment of volume status. However, performing $\mathrm{CT}$ in critically ill patients is associated with potential risks since CT requires patient transport and is associated with $\mathrm{X}$-ray exposure.

TPTD was used as the reference method for assessment of cardiac preload and EVLWI in the present study. It is important to emphasize that this advanced and invasive hemodynamic monitoring technique has some inherent limitations and can not be considered as an absolute gold standard for determination of a patient's volume status: Since an arterial catheter and a central venous catheter is required to perform TPTD measurements, this method is usually restricted to ICUs and is not available for emergency department or normal ward patients. Although there are data from previous studies that TPTD-derived volumetric parameters of cardiac preload might predict volume responsiveness more accurately than CVP or pulmonary artery wedge pressure (obtained using a pulmonary artery catheter), in certain patients with cardiovascular disorders (e.g. intracardiac left-right-shunt, valvulopathies, aortic aneurysms) the TPTD-based determination of cardiac preload (GEDVI) can be adulterated $[9,10,38,39]$. In addition, the recommended and established thresholds for normal values of hemodynamic variables derived from TPTD were defined based on data from studies in selected populations of patients and might therefore not be unrestrictedly applicable for all patients. Results from an autopsy study recently confirmed the recommended normal value of EVLWI defined by the manufacturer of the device [14]. Regarding GEDVI, there is evidence from one trial that normal values of this preload parameter should be adjusted to sex and age in neurosurgery patients [40]. In addition, a recent study in medical ICU patients suggested that GEDVI might be corrected for cardiac ejection fraction for better prediction of preload [41].

\section{Limitations of the study}

- In the present study we compared radiographic CTbased estimation of hemodynamic variables to invasively assessed hemodynamic parameters using TPTD. Although TPTD is established for assessment of cardiac preload and pulmonary hydration, this technique has some inherent limitations and can therefore not be considered the absolute gold standard method for determination of hemodynamics.

- This monocentric study was conducted retrospectively in a medical ICU and the results are therefore not generalizable to other patient populations. The findings of this pilot study rather need to be confirmed in a prospective trial in a larger number of patients.

- Another limitation of this retrospective data analysis is that there was a time interval of a mean of 2 hours between TPTD and the CT scan. In a future prospective study TPTD should be performed directly before and after CT.

\section{Conclusions}

The results of our study suggest that estimation of GEDVI and EVLWI using standard CT scans of the thorax is not accurate in critically ill patients in a clinical setting without the support of quantitative CT analyzing software when compared to invasive assessment of these variables using TPTD. At this point CT-based estimation can not provide reliable and reproducible quantification of fluid overload, low cardiac preload or pulmonary edema defined by the TPTD variables GEDVI and EVLWI and therefore seems to be of limited use for early assessment of volume status in critically ill patients. However, it should be mentioned, that prognostic capabilities of radiographic estimation can probably be improved by interdisciplinary training and more detailed clinical information provided to the radiologist as well as improved diagnostic algorithms. An intriguing approach in further prospective trials in a larger number of patients could be to develop an objective 


\section{formula for CT-based estimations of GEDVI and EVLWI.}

\begin{abstract}
Abbreviations
ALI: acute lung injury; ARDS: acute respiratory distress syndrome; BCF: bias correction factor; ccc: concordance correlation coefficient proposed by Lin; CT: computed tomography; CVP: central venous pressure; EVLW: extravascular lung water; EVLWl: extravascular lung water index; GEDV: global end-diastolic volume; GEDVI: global end-diastolic volume index; HU: Hounsfield units; ICU: intensive care unit; NPV: negative predictive value; PPV: positive predictive value; R1: radiologist 1; R2: radiologist 2; SE: standard error; TPTD: transpulmonary thermodilution; $95 \% \mathrm{Cl}$ : 95\% confidence interval.
\end{abstract}

\section{Author details}

'II. Medizinische Klinik und Poliklinik, Klinikum rechts der Isar der Technischen Universität München, Ismaninger Strasse 22, D-81675 München, Germany. ${ }^{2}$ Institut für Röntgendiagnostik, Klinikum rechts der Isar der Technischen Universität München, Ismaninger Strasse 22, D-81675 München, Germany. ${ }^{3}$ Radiologie, Klinikum Memmingen, Bismarck Strasse 23, D-87700 Memmingen, Germany. ${ }^{4}$ Institut für Medizinische Statistik und Epidemiologie, Klinikum rechts der Isar der Technischen Universität München, Ismaninger Strasse 22, D-81675 München, Germany.

\section{Authors' contributions}

$B S, V P, C S$ and $W H$ contributed to the conception and design of the study. They were responsible for acquisition, analysis and interpretation of data. BS and WH drafted the manuscript. RMS participated in its design and coordination and helped to draft the manuscript. KH and JS are experienced radiologists. They both participated in the design of the study and read the CT scans. TS participated in the design of the study and performed the statistical analysis. All authors read and approved the final manuscript.

\section{Competing interests}

There is no financial support for the research to disclose. WH is member of the Medical Advisory Board of Pulsion Medical Systems AG. All other authors have no conflict of interest to declare.

Received: 12 February 2011 Accepted: 23 May 2011

Published: 23 May 2011

\section{References}

1. Katz SD: Blood volume assessment in the diagnosis and treatment of chronic heart failure. Am J Med Sci 2007, 334(1):47-52.

2. Chung HM, Kluge R, Schrier RW, Anderson RJ: Clinical assessment of extracellular fluid volume in hyponatremia. Am J Med 1987, 83(5):905-908

3. Badgett RG, Lucey CR, Mulrow CD: Can the clinical examination diagnose left-sided heart failure in adults? Jama 1997, 277(21):1712-1719.

4. McGee S, Abernethy WB, Simel DL: The rational clinical examination. Is this patient hypovolemic? Jama 1999, 281(11):1022-1029.

5. Saugel B, Ringmaier S, Holzapfel K, Schuster T, Phillip V, Schmid RM, Huber W: Physical examination, central venous pressure, and chest radiography for the prediction of transpulmonary thermodilutionderived hemodynamic parameters in critically ill patients: A prospective trial. J Crit Care 2011.

6. Ely EW, Smith AC, Chiles C, Aquino SL, Harle TS, Evans GW, Haponik EF: Radiologic determination of intravascular volume status using portable, digital chest radiography: a prospective investigation in 100 patients. Crit Care Med 2001, 29(8):1502-1512.

7. Halperin BD, Feeley TW, Mihm FG, Chiles C, Guthaner DF, Blank NE: Evaluation of the portable chest roentgenogram for quantitating extravascular lung water in critically ill adults. Chest 1985 , 88(5):649-652

8. Baudendistel L, Shields JB, Kaminski DL: Comparison of double indicator thermodilution measurements of extravascular lung water (EVLW) with radiographic estimation of lung water in trauma patients. J Trauma 1982, 22(12):983-988.

9. Michard F, Alaya S, Zarka V, Bahloul M, Richard C, Teboul JL: Global enddiastolic volume as an indicator of cardiac preload in patients with septic shock. Chest 2003, 124(5):1900-1908.
10. Reuter DA, Felbinger TW, Schmidt C, Kilger E, Goedje O, Lamm P, Goetz AE: Stroke volume variations for assessment of cardiac responsiveness to volume loading in mechanically ventilated patients after cardiac surgery. Intensive Care Med 2002, 28(4):392-398.

11. Fernandez-Mondejar E, Rivera-Fernandez R, Garcia-Delgado M, Touma A, Machado J, Chavero J: Small increases in extravascular lung water are accurately detected by transpulmonary thermodilution. J Trauma 2005, 59(6):1420-1423, discussion 1424.

12. Katzenelson R, Perel A, Berkenstadt H, Preisman S, Kogan S, Sternik L, Segal E: Accuracy of transpulmonary thermodilution versus gravimetric measurement of extravascular lung water. Crit Care Med 2004, 32(7):1550-1554

13. Kuzkov W, Kirov MY, Sovershaev MA, Kuklin VN, Suborov EV, Waerhaug K, Bjertnaes L: Extravascular lung water determined with single transpulmonary thermodilution correlates with the severity of sepsisinduced acute lung injury. Crit Care Med 2006, 34(6):1647-1653.

14. Tagami T, Kushimoto S, Yamamoto Y, Atsumi T, Tosa R, Matsuda K, Oyama R, Kawaguchi T, Masuno T, Hirama H, et al: Validation of extravascular lung water measurement by single transpulmonary thermodilution: human autopsy study. Crit Care 2010, 14(5):R162.

15. Renner J, Gruenewald M, Brand P, Steinfath M, Scholz J, Lutter G, Bein B: Global end-diastolic volume as a variable of fluid responsiveness during acute changing loading conditions. I Cardiothorac Vasc Anesth 2007, 21(5):650-654.

16. Muller L, Louart G, Bengler C, Fabbro-Peray P, Carr J, Ripart J, de La Coussaye JE, Lefrant JY: The intrathoracic blood volume index as an indicator of fluid responsiveness in critically ill patients with acute circulatory failure: a comparison with central venous pressure. Anesth Analg 2008, 107(2):607-613.

17. Craig TR, Duffy MJ, Shyamsundar M, McDowell C, McLaughlin B, Elborn JS, McAuley DF: Extravascular lung water indexed to predicted body weight is a novel predictor of intensive care unit mortality in patients with acute lung injury. Crit Care Med 2010, 38(1):114-120.

18. Phillips CR, Chesnutt MS, Smith SM: Extravascular lung water in sepsisassociated acute respiratory distress syndrome: indexing with predicted body weight improves correlation with severity of illness and survival. Crit Care Med 2008, 36(1):69-73.

19. Belda FJ, Aguilar G, Teboul JL, Pestana D, Redondo FJ, Malbrain M, Luis JC, Ramasco F, Umgelter A, Wendon J, Kirov M, Fernandez-Mondejar E: Complications related to less-invasive haemodynamic monitoring. $\mathrm{Br} J$ Anaesth 2011, 106(4):482-486.

20. Gattinoni L, Caironi P, Pelosi P, Goodman LR: What has computed tomography taught us about the acute respiratory distress syndrome? Am J Respir Crit Care Med 2001, 164(9):1701-1711.

21. Tagliabue M, Casella TC, Zincone GE, Fumagalli R, Salvini E: CT and chest radiography in the evaluation of adult respiratory distress syndrome. Acta Radiol 1994, 35(3):230-234.

22. Desai SR, Hansell DM: Lung imaging in the adult respiratory distress syndrome: current practice and new insights. Intensive Care Med 1997, 23(1):7-15.

23. Rouby JJ, Puybasset L, Cluzel P, Richecoeur J, Lu Q, Grenier P: Regional distribution of gas and tissue in acute respiratory distress syndrome. II. Physiological correlations and definition of an ARDS Severity Score. CT Scan ARDS Study Group. Intensive Care Med 2000, 26(8):1046-1056.

24. Hedlund LW, Vock P, Effmann EL, Lischko MM, Putman CE: Hydrostatic pulmonary edema. An analysis of lung density changes by computed tomography. Invest Radiol 1984, 19(4):254-262.

25. Kato $S$, Nakamoto T, lizuka M: Early diagnosis and estimation of pulmonary congestion and edema in patients with left-sided heart diseases from histogram of pulmonary CT number. Chest 1996, 109(6):1439-1445.

26. Schefold JC, Storm C, Bercker S, Pschowski R, Oppert M, Kruger A, Hasper D: Inferior vena cava diameter correlates with invasive hemodynamic measures in mechanically ventilated intensive care unit patients with sepsis. J Emerg Med 2010, 38(5):632-637.

27. Sakka SG, Ruhl CC, Pfeiffer UJ, Beale R, McLuckie A, Reinhart K, MeierHellmann A: Assessment of cardiac preload and extravascular lung water by single transpulmonary thermodilution. Intensive Care Med 2000, 26(2):180-187.

28. Bland JM, Altman DG: Statistical methods for assessing agreement between two methods of clinical measurement. Lancet 1986, 1(8476):307-310. 
29. Lin LI: A concordance correlation coefficient to evaluate reproducibility. Biometrics 1989, 45(1):255-268.

30. Kuzkov W, Suborov EV, Kirov MY, Waerhaug K, Mortensen R, Kuklin VN, Nordhus KC, Bjertnaes LJ: Radiographic lung density assessed by computed tomography is associated with extravascular lung water content. Acta Anaesthesiol Scand 2010, 54(8):1018-1026.

31. Kirov MY, Kuzkov W, Fernandez-Mondejar E, Bjertnaes L: Measuring extravascular lung water: animals and humans are not the same. Crit Care 2006, 10(4):415.

32. Rossi P, Wanecek M, Rudehill A, Konrad D, Weitzberg E, Oldner A: Comparison of a single indicator and gravimetric technique for estimation of extravascular lung water in endotoxemic pigs. Crit Care Med 2006, 34(5):1437-1443.

33. Easley RB, Mulreany DG, Lancaster CT, Custer JW, Fernandez-Bustamante A Colantuoni E, Simon BA: Redistribution of pulmonary blood flow impacts thermodilution-based extravascular lung water measurements in a model of acute lung injury. Anesthesiology 2009, 111(5):1065-1074.

34. Malbouisson LM, Preteux F, Puybasset L, Grenier P, Coriat P, Rouby JJ: Validation of a software designed for computed tomographic (CT) measurement of lung water. Intensive Care Med 2001, 27(3):602-608.

35. Patroniti N, Bellani G, Maggioni E, Manfio A, Marcora B, Pesenti A: Measurement of pulmonary edema in patients with acute respiratory distress syndrome. Crit Care Med 2005, 33(11):2547-2554.

36. Marik PE, Baram M, Vahid B: Does central venous pressure predict fluid responsiveness? A systematic review of the literature and the tale of seven mares. Chest 2008, 134(1):172-178.

37. Cheatham ML, Malbrain ML: Cardiovascular implications of abdominal compartment syndrome. Acta Clin Belg Suppl 2007, 1:98-112.

38. Breukers RM, Groeneveld AB, de Wilde RB, Jansen JR: Transpulmonary versus continuous thermodilution cardiac output after valvular and coronary artery surgery. Interact Cardiovasc Thorac Surg 2009, 9(1):4-8.

39. Osman D, Ridel C, Ray P, Monnet X, Anguel N, Richard C, Teboul JL: Cardiac filling pressures are not appropriate to predict hemodynamic response to volume challenge. Crit Care Med 2007, 35(1):64-68.

40. Wolf S, Riess A, Landscheidt JF, Lumenta CB, Friederich P, Schurer L: Global end-diastolic volume acquired by transpulmonary thermodilution depends on age and gender in awake and spontaneously breathing patients. Crit Care 2009, 13(6):R202.

41. Malbrain ML, De Potter TJ, Dits H, Reuter DA: Global and right ventricular end-diastolic volumes correlate better with preload after correction for ejection fraction. Acta Anaesthesiol Scand 2010, 54(5):622-631.

doi:10.1186/1757-7241-19-31

Cite this article as: Saugel et al:: Computed tomography to estimate cardiac preload and extravascular lung water. A retrospective analysis in critically ill patients. Scandinavian Journal of Trauma, Resuscitation and Emergency Medicine 2011 19:31.

\section{Submit your next manuscript to BioMed Central and take full advantage of:}

- Convenient online submission

- Thorough peer review

- No space constraints or color figure charges

- Immediate publication on acceptance

- Inclusion in PubMed, CAS, Scopus and Google Scholar

- Research which is freely available for redistribution

Submit your manuscript at www.biomedcentral.com/submit
Biomed Central 